\title{
Language Acquisition and Cultural Identity Among Modern Chinese Minority College Students*
}

\author{
Huanan $\mathrm{Su}$ \\ College of Arts and Sciences, University of the Cordilleras, Baguio City, Philippines \\ Fengyi Ma \\ Office of Foreign Languages, Guilin Medical University, Guilin, Guangxi, China
}

\begin{abstract}
This research attempts to have an empirical analysis on the relationship between the acquisition of language and the cultural identity among modern Chinese minority college students, and try to show an empirical view of how the acquisition of language matters with the cultural identity from one side as well as the mutual influences reflected from the relationship between language acquisition and cultural identity from the other side. The research employs mainly three analytical methods including method of theoretical analysis, method of comparative analysis and method of questionnaire to acquire a full understanding of the relationship between the acquisition of language and the cultural identity among modern Chinese minority college students. The current study data shows that compared with the local language, modern Chinese minority college students use Mandarin more in most of the time and occasions. At the same time, while acknowledging the importance of their local language, modern Chinese minority students also strongly advocate the promotion of Mandarin and English. Conclusion: Language acquisition and cultural identity are closely related. This is mainly reflected in the fact that language acquisition deeply reflects the elements of cultural identity, while cultural identity deeply reciprocally affects the way of language acquisition. The cultural identity of modern Chinese minority college students has determined the series of characteristics and methods they exhibit in the process of their language acquisition. The close relationship between language acquisition and cultural identity has provided great support and enlightenment both theoretically and practically for the majority of language educators.
\end{abstract}

Index Terms - language acquisition, cultural identity, Modern Chinese Minority College Students

\section{INTRODUCTION}

Stepping into the $21^{\text {st }}$ century, we are faced with a heated interactive relationship between language and culture, which is also an area that urgently needs in-depth research. One of the challenging breakthroughs in contemporary language teaching research is also to put culture into the language environment, especially from a cultural standpoint to understand language acquisition in the future, which is actually one of the key areas of future linguistic research.

Regarding the relationship between language acquisition and culture, the world of academia has put forward a variety of views, one of which is the "Sapir-Whorf Hypothesis", which believes that language structure is the origin and decisive factor of cultural structure (Larsen-Freeman, 2018), the opposite is from the Marxist viewpoint, which maintains that the social and cultural structure is the decisive factor of language (Kramsch, 2000).

At the same time, positivism believes that there is only "partnership" and correlation but no causality between language structure and social cultural structure. There are also viewpoints that support such a theory that language is the carrier of culture, and that the basic relationship between language acquisition and cultural identity are consistent, and so on.

The development of cultural identity has historical continuity, and this continuity is achieved through language acquisition activities. In China, since there is a large population, the issue of the relationship between the acquisition of language and the cultural identity among modern Chinese minority college students has become an important issue that we cannot avoid (Lv, 2010).

In this research, by introducing the points of language acquisition and cultural identity, the researchers try to analyze the deep relationship between language acquisition and cultural identity among modern Chinese minority college students from the perspective of their language attitudes, language recognition as well as their language understanding.

In other words, discussing the issue of the study from the perspective of language attitudes, recognition and understanding will help modern Chinese minority college students as well as all paper readers understand more easily \footnotetext{
China.

* This research is supported by The Project of Scientific Research Start-up Fees for Talent Introduction of Guilin Medical University, Guilin,
} 
and directly the deep-seated relationship between language acquisition and cultural identity.

\section{LITERATURE REVIEW}

This research mainly reviews literatures about language acquisition and cultural identity. Besides, some basic information related to the modern Chinese minority college students will also be introduced and explained so as to help all readers fully understand the relationship between language acquisition and cultural identity among modern Chinese minority college students.

\section{A. Connotation of Language Acquisition}

Before knowing what exactly language acquisition is, we have to know what language is from the beginning. General linguistics believes that language is a system composed of vocabulary and grammar (Haugen, 1972). This is the most basic connotation of language. However, if you look at it from the perspectives of sociolinguistics, historical linguistics, cultural linguistics, etc., various interpretations will be drawn. It thus can be seen that it is not easy to define a language that everyone recognizes (Cho, 2000).

Language emerges and develops along with the development of human society. The connotation of language has different views due to different eras and different schools. Generally speaking, the connotation of language can be defined as the most important symbol system used by humans in communication and thinking. Language is unique to human beings. Humans can use a variety of tools for communication and thinking, but language is the most important tool that humans cannot leave.

When people speak, it is a compound phenomenon. Language is not equal to speaking. It is only one aspect of the compound phenomenon of speaking, that is, a set of symbols used in speaking, which is composed of voice, vocabulary, semantics, grammar and other subsystems, are called language (Faretta-Stutenberg \& Morgan-Short, 2018). The connotation of language includes a relatively complete abstract symbol system that exists in the brains of all members of the community, which is universal, immaterial and abstract.

And then, what is language acquisition?

The so-called language acquisition is also the symmetry of language learning. It generally means that people naturally, subconsciously, and gradually master a language in a speech environment (Benson, 2017). In the general grammar idea of generative linguistics, the rules of each language are interpreted as follows: the same set of universal grammar principles and specific values of parameters are adjusted to their specific states.

We all know about first language acquisition. The acquisition of the first language is the process by which children gradually learn a certain state of the universal grammar. This process involves not only the activation of the natural language ability, but also the mastery of the specific state of grammar and parameter values (Faretta-Stutenberg \& Morgan-Short, 2018). Therefore, cognitive linguistics may tend to think that the acquisition of the first language also involves the semantic learning of language knowledge.

We also have second language acquisition. As for the acquisition of the second language, this is actually on the premise that the specific state of the universal grammar presented in the first language has been mastered, and then the specific state presented in the second language is learned (Au, 1983). Although these two states can be converted to each other through conversion rules, however, in many cases, learners may not realize that these conversion rules are actually learned by their intuition.

Second Language Acquisition, also known as SLA, usually refers to the learning of any other language after a person has acquired his mother tongue. People generally study second language acquisition from the perspectives of society, psychology, and linguistics. As an independent discipline, the study of second language acquisition was probably formed in the late 1960s and early 1970s. SLA describes the learners' second language characteristics and their development and changes, as well as the common characteristics and individual differences that learners have when learning a second foreign language. At the same time, it also analyzes the internal and external factors that affect second language acquisition.

Compared with other social sciences, second language acquisition research is a new field. Therefore, the second language acquisition mostly borrows the methods of mother tongue research, pedagogy research or other related subject-based research. In a nutshell, research in this field is to systematically explore the nature and processes of second language acquisition. Its main goal is to describe how learners acquire a second language and explain why learners can acquire a second language. Since entering the $21^{\text {st }}$ century, the research scope of second language acquisition is much wider than that in the 1970s and 1980s. This is mainly because its research scope involves linguistics, psychology, psycholinguistics, pragmatics, sociolinguistics and many other aspects (Benson, 2017).

From another perspective, as an important branch of applied linguistics, second language acquisition mainly studies the processes and results of people learning a second language. Its purpose is to objectively describe the language learning ability of the learners and communicative ability of the language learners, and to make in-depth explanations based on a certain scientific information database.

The early theory of second language acquisition was a vassal of the teaching method and existed to serve to improve the quality of teaching (Davin \& Heineke, 2017). In 1967, Larry Selinker put forward the inter-language theory for the first time in the book Language Transfer. Since then, the theory of second language acquisition has its own research 
field and has become an independent subject. The current research on second language acquisition involves three major areas, namely the study of inter-language, the study of learners' internal factors as well as the study of learners' external factors.

Ellis (1994), professor of second language, teaching English at the School of Education, Temple University, Philadelphia, wrote the masterpiece Research on Second Language Acquisition, which became a classic textbook in the field. The book is divided into seven parts, mainly including three aspects. According to Ellis (1994), in the first aspect, the book summarizes the main theories about the nature of learner language, including learner errors, development patterns, language variables and pragmatic features. In the second aspect, the book mainly describes the role of social factors and language input, including language transfer, epistemological interpretation and language universality. In the third aspect, the book shifts the focus of discussion from learning to learners, discussing individual differences in second language acquisition and learning strategies.

In a nutshell, the masterpiece makes a critical analysis of the current research on second language acquisition based on relevant data analysis, theoretical construction and practical application (Benson, 2017). Because of this, many modern language researchers and language learners regard that book as the most basic theoretical book as well as bibliography for studying second language acquisition. Broadly speaking, to a certain extent, this has also promoted the theoretical development and practical breakthrough of second language acquisition within the field of linguistics in the $21^{\text {st }}$ century.

Through the above introduction of the connotation of language as well as language acquisition, we cannot have an overall but can have a general understanding of language acquisition. Besides, in reality, it is also necessary to discuss some of the important attributes of the language acquisition, which include the semiotic, systematic, generative and national aspects.

\section{B. Nature of Cultural Identity}

In the past century, scholars have roughly defined the nature of cultural identity from three different perspectives. First of all, from the perspective of anthropology, it is emphasized that the nature of cultural identity is related to the nature of human beings. As the basic form of human beings different from animals, culture is essentially an artificial object relative to nature, and the nature of cultural identity is creation (Baggett, 2016). Secondly, from the perspective of social functions, it is emphasized that cultural identity is productivity, information and knowledge, and a cultural mentality and symbol system. Finally, from the perspective of communication studies, it is emphasized that communication is the nature of cultural identity. Without communication, cultural identity will take place nowhere.

Anthropologist Edward Tylor once proposed an understanding of the nature of cultural identity in his book Primitive Culture, which is very influential worldwide and is one of the most extensive and precise definitions. His famous definition is that the so-called culture and cultural identity is a combination that includes knowledge, beliefs, art, morals, laws, customs, and any other abilities and habits acquired by individuals as members of society. In his definition of the nature of cultural identity, he has emphasized knowledge, customs, abilities, habits, etc., rather than concrete objects.

In addition, there is another definition of nature of cultural identity, which refers to all the life styles created in history, including the explicit and the implicit, the reasonable and the unreasonable. Such life styles exist as a potential guide for human's behaviours in a certain period.

In accordance with different research fields, the perspectives of the definition of cultural identity are also different. When different cultures collide, issues of identity or belonging often arise. Therefore, at present, in the actual application processes, cultural identity is mostly used in cross-cultural communication researches such as studying the cultural identity of overseas Chinese, or the cultural identity of foreign language learners, etc (Chen, 1985). These studies are often accompanied by studies of ethnic identity.

Cultural identity refers to the confirmation and submission of a certain cultural group or a certain cultural behaviour pattern. It is very comprehensive to define cultural identity as the confirmation of the common culture between people or between individuals and groups (Baggett, 2016). Using the same cultural symbols, following a common cultural concept, and adhering to a common mode of thinking and behavioural norms are the basis for cultural identity. In the book Cross-cultural Communication, Dr. Liu Shuang also points out that cultural identity is the sense of identity of members of a cultural group with their own cultural belonging, and its characteristics are manifested by the words and actions of members of a cultural group.

Researchers in this article also believe that cultural identity refers to the process by which individuals perceive the worldview, values, and attitudes of a cultural group under the influence of different social environments and different cultures, and then generate emotions. It is embodied through language, values, and behaviour, and it is a process of confirming a member's belonging (Couto, 2014). This is also the individual's awareness and internal definition of the same characteristics of a certain culture, accompanied by other identities, including national identity, ethnic identity, and so on.

It is worth mentioning that Professor Wang Guangwu, an internationally renowned expert on overseas Chinese issues, puts forward the concept of Chinese identity in The Study on Chinese Identity in Southeast Asia, which mainly includes four types of identity: national identity, cultural identity, ethnic identity and class identity. Cultural identity mainly includes two aspects. The first aspect is the Chinese cultural norms that the Chinese believe are bounded on them. The second aspect is the modern cultural norms that the Chinese consider useful and necessary to accept, including all social 
customs that reflect the complexities of diverse societies (Hao, 2002).

In the study of Chinese cultural identity in Southeast Asia, Dr. Yang Yiyin analyzes the concept of cultural identity as the individual's sense of belonging and inner commitment to the culture and cultural group to which he belongs. She believes that cultural identity is a kind of social identity, and according to the theory of social identity and self-categorization, she believes that the construction of cultural identity is a dynamic psychological process. She points out that when people choose their own identities, they are mostly based on their language and cultural values as well as cultural customs, which have strong flexibility and are closely related to the social environment of the individual existence.

The social identity obtained by searching for differences between us and others is the way and process for individuals to gain a sense of belonging to a cultural group. This is because once cultural identity is established, it is independent and dynamic, internalized as a part of personality, and can have long-term stability. In the dimension of cultural identity, according to the theory of social identity, people classify cultural identity into three stages, including the cognitive stage, which includes a basic understanding of the other's culture; emotional stage, which includes committing the other's culture and having a good impression of the cultural group; behavioural stage, which includes participating or imitating and learning from each other's culture.

Professor Tomlinson has stated in Cultural Imperialism that all cultural identities are representations of belonging and an imaginary sense of belonging. His definition focuses on the emotional aspect of cultural identity, and the definition of cultural identity relies on the behaviour of individuals or group members (Hecht, 2005). These might include showing their group belonging, their understanding of the conditions required to become members of the group, and the acceptance of the group members, as well as the ability to participate in social practice in a different way.

To sum up, cultural identity is a process of confirming cultural belonging. It is a choice made after comparison between different cultures. It divides cultural identity into three dimensions, including cognition, emotion, and behaviour. In essence, cultural identity is a kind of social identity, which affects individuals' social identity and self-identity, and guides people to love and to be faithful with their own culture, thereby preserving and developing their cultural values in a deeper psychological structure.

There is no fixed statement about the nature of cultural identity. The discussion on the nature of cultural identity at home and abroad has continued for a long time. There are general discussions and academic discussions, but in the end there is no conclusion. Understanding of culture as well as cultural identity is meaningful (Stephen, 2014). When it comes to engaging in cross-cultural communication research, cultural comparison is a crucial issue. If there is a different understanding of the nature of cultural identity, the comparison cannot be accurate, and even the things being compared may be different.

Besides, the definition of terminology is the prerequisite for studying any discipline. The accuracy of the definition of terminology for the positioning of the nature of cultural identity is related to the scientificity and precision of the discipline itself (Hecht, 2005). This is to say that we ought to have a substantive discussion of ideas without defining the concept and nature of culture as well as cultural identity.

In addition, discussing the nature of culture as well as cultural identity can help us further understand the nature and characteristics of culture. Scholars in various disciplines want to give accurate explanations of the nature of cultural identity. However, their explanations have the characteristics of the discipline and have their own different focuses, so much so that they all reveal the nature of cultural identity to varying degrees; nevertheless, they have already had a deep understanding of the nature of culture as well as cultural identity, which is actually necessarily needed.

\section{Cultural Identity of Modern Chinese Minority College Students}

Continued above with 2.2, the cultural identity of Chinese minority college students is seen as their overall self-perception, including the sharing of information and elements such as world outlook, values, attitudes and beliefs. Therefore, this also calls on all Chinese minority college students to realize that cultural identity involves unique behaviours of a race, ethnicity, region, economy, or other social group that distinguish themselves from others.

Of course, in today's China, the consciousness of cultural identity of Chinese minority college students is getting more and more attention. Chinese minority college students' awareness of cultural identity includes various types of identities related to different social and cultural groups (Lv, 2010). At the same time, it also includes ethnic identity, national identity, and group identity, etc.

In the group of Chinese college students, Chinese minority college students are a special group. When they first enter the university campus, they face cultural shocks and influences from different places. This is because the culture they face is a mainstream culture within China, and the culture of ethnic minority college students is their own originally unique culture (Luo, 1989). This kind of culture in their own body has their own national cultural characteristics and cultural connotations, and because of this, it makes them appear to be different from the mainstream group to a certain extent.

In that case, most Chinese minority college students adopt a cultural adaptation strategy called "Cultural Integration" (Xiao, 1990). On the one hand, they will accept the social views from the influence of mainstream culture to better adapt to the university's living environment, humanistic environment and so on. On the other hand, they also maintain the parental culture of their own ethnic minorities and retain their cultural identity. In this way, they will better adapt to the life of college and get along with more and more college peers. 
Of course, sometimes, Chinese minority college students encounter moments when the mainstream culture and their own national culture conflict, but they can quickly find out the problem, actively analyze the cultural problem, and solve it sensibly (Zhu, 2003). Chinese minority college students with excellent cultural identity and values can handle the problems that arise between different cultures keenly. This kind of cultural identity also helps them better understand the relationship between their own culture and the mainstream culture, so as to face the various cultures in the university with a better inner state (Luo, 1989).

Since cultural identity refers to a process in which individuals recognize and approve of their own cultures within individuals and groups, in the process of language learning, Chinese minority college students continue to deepen their cultural identity and give a certain degree of recognition and tolerance to other foreign cultures as well as their cultural identities.

\section{METHODOLOGY}

Methodology of this research mainly talks about methods of the research paper. Since this is about an empirical analysis of language acquisition and cultural identity among Chinese minority college students, the researchers will focus on the analysis of the language acquisition and cultural identity and the interpretation of how the acquisition of language connects with culture understanding as well as cultural identity.

\section{A. Research Problem}

This research paper intends to have a detailed understanding of language acquisition and cultural identity among modern Chinese minority college students, as is mentioned at the beginning of the paper. Based on what has been introduced and analyzed in literature review, this research makes efforts to answer such a question that how significant language acquisition and cultural identity are among modern Chinese minority college students as well as what the actual relationship between language acquisition and cultural identity is among modern Chinese minority college students.

Therefore, the research problem of the research paper is as follows: what is the actual relationship between language acquisition and cultural identity among modern Chinese minority college students?

\section{B. Research Participants}

This research has selected two groups of modern Chinese minority college students with one group of them are female and another group of them are male from a medical university in China as the research participants. The total number of the research participants is eighty. Among the selected Chinese minority college students, they come from the same medical university, but they have different educational backgrounds. Their current majors are different, and the language learning environments they are exposed to are also different from each other before they enter the university. Selecting college students based on such criteria is more conducive to the research in terms of the reliability and validity of this research topic.

\section{Research Site}

The researchers have chosen a medical university from Guangxi Province, China as the research site. In the process of conducting the research, in order to collect relevant data more directly and objectively, the research was carried out at the same research site from the beginning to the end. This is also aimed at providing a more convenient and objective environment for data research as well as data analysis in the later stage of the research.

\section{Research Methods}

Qualitative and quantitative methods are employed to carry out this research. To specify, three analytical methods including the method of literature synthesis, the method of comparative analysis, and the method of questionnaire are introduced as follows.

\section{Method of Theoretical Analysis}

The theoretical analysis method is the most basic method used in this research. The researchers have read extensively domestic and foreign books and papers on language acquisition and culture understanding, especially those that are latest published or known. This will make the study as theoretical and original as possible.

The method of theoretical analysis is opposite to the empirical analysis method. It is a scientific analytical method to understand the nature and laws of things through rational thinking on the basis of perceptual knowledge. Theoretical analysis method is a form of theoretical thinking and an advanced form of scientific analysis. It decomposes things into various components, characteristics, attributes, relations, etc. The results of the theoretical analysis method are thus defined and established in essence through comprehensive analysis, so as to grasp the regularity of things in the world.

When conducting the method of theoretical analysis, the researchers realize that some things must be done. On the one hand, under the guidance of a certain theory, the analysis of social phenomena and processes requires social science theories, as well as the philosophical theories of dialectical materialism. On the other hand, in addition to formal logic methods such as induction and deduction, analysis and synthesis, the theoretical analysis method should also use dialectical logic methods such as contradiction analysis, etc. Besides, the researchers also know that within this study 
the theoretical analysis and the practical testing should be combined in order to be verified in time.

An organic combination of theoretical analysis and empirical analysis is not only conducive to the realization of dialectical analysis, but also more realistic for the study. In view of this, the researchers thus read and analyze through a qualitative means in order to analyze the related theories of language acquisition and cultural identity more realistically and rationally, and extract the view that the acquisition of language and the understanding of culture are closely integrated, and then draw the possible conclusions. By theoretically analyzing a large number of relevant documents and data, this study strives to demonstrate that the analytical processes and final conclusions about the relationship between the acquisition of language and the understanding of culture in terms of cultural identity are comprehensive and objective enough.

\section{Method of Comparative Analysis}

A comparative analysis method is also adopted for the research. On the one hand, this method can comprehensively sort out some necessary thoughts of the language acquisition and cultural identity and unify these scattered thoughts into a systematic and complete theory. The related theories of language acquisition are combined with the related theories of culture understanding, so as to have a deeper understanding of the transition from language acquisition to cultural identity.

The use of comparative analysis methods is more conducive for the researchers to accurately analyze the relationship between the acquisition of language and the understanding of culture, and to locate the roles of the language acquisition and the cultural identity from the perspective of culture understanding. Specially, with the help of a comparative viewpoint, the acquisition of language will also incorporate elements of culture, thus promoting the development and understanding of culture, and at the same time allowing language acquisition and cultural identity to better display a new face of the entire world.

\section{Method of Questionnaire}

This research also adopts the method of questionnaire to facilitate the outcome of the study. The method of questionnaire is a research method widely used in many social surveys nowadays. The so-called questionnaire refers to the materials used for a variety of collections of data as well as statistics. Questionnaires in a research will generally express questions in the form of questioning. The method of questionnaire is a method for the researcher to use controlled measurement to measure the problems related under a certain research or study, so as to collect reliable data and information. The two main advantages of the method of questionnaire are standardization and low cost. The method of questionnaire uses a well-designed questionnaire tool to conduct surveys; therefore the design of the questionnaire requires standardization and measurability.

In the questionnaire of this research, the quantitative research is mainly to understand the relationship between language acquisition, language awareness, language attitude and cultural identity among Chinese minority college students. At the same time, it is also meant to understand whether these factors mentioned above affect the changes in cultural identity of Chinese minority college students in the process of language acquisition. This research uses EXCEL 2010 and the statistical software of SPSS 23.0 as well as other related tools to further analyze and explain the results of the questionnaire.

Overall, the three analytical methods mentioned above will lay a solid theoretical and methodological foundation for the research and writing of this research paper. It will also provide a necessary and important premise for the writing of the findings which will be shown in the following chapter.

\section{FINDINGS}

In the findings, the researchers will mainly show a detailed description of the data collected from the questionnaires. The results of the research will also be shown via EXCEL 2010 as well as some other forms of tables or charts. At the same time, a brief interpretation of the relationship between language acquisition and cultural identity among Chinese minority college students will also be introduced within the chapter.

A. Reality of Language Usage 


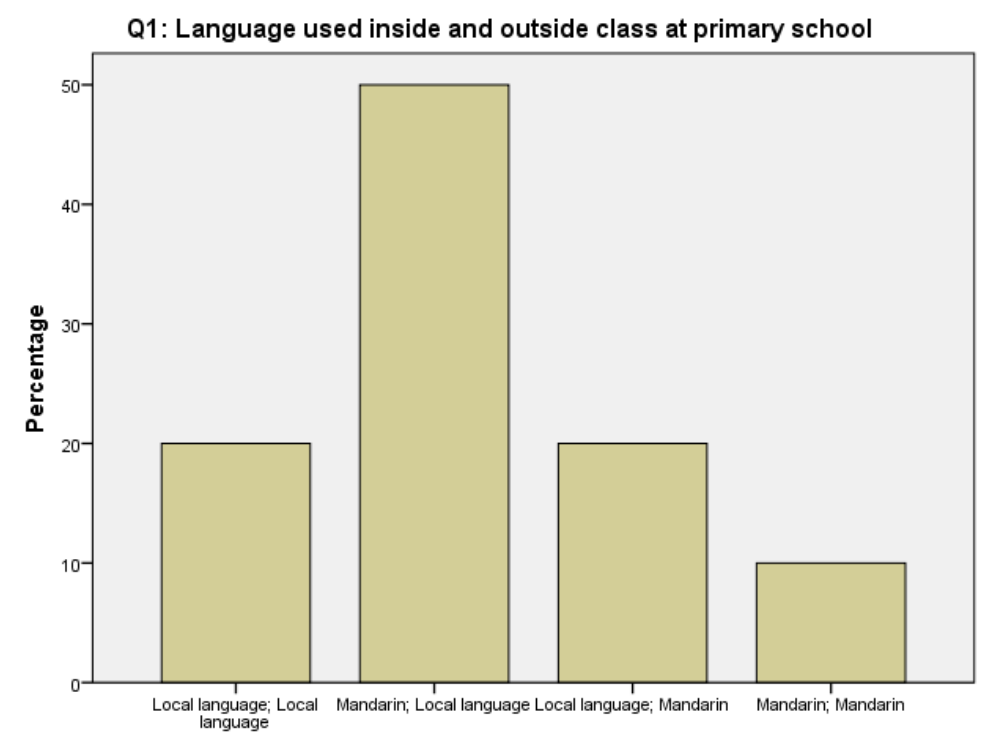

According to the data of Q1, we can clearly see that the percentage of language uses varies from one to another. The highest percentage of language used inside and outside class at primary school goes to Mandarin/local language, which is 50\%. The lowest percentage of language used inside and outside class at primary school goes to Mandarin/Mandarin, which is $10 \%$ only. Besides, the percentage of local language used inside and outside class at primary school is the same as that of Local language/Mandarin, which is $20 \%$. The data from the above chart illustrates that Mandarin is mostly spoken inside class at primary school while most of the time they speak local language outside class.

Q2: Language used inside and outside at secondary school

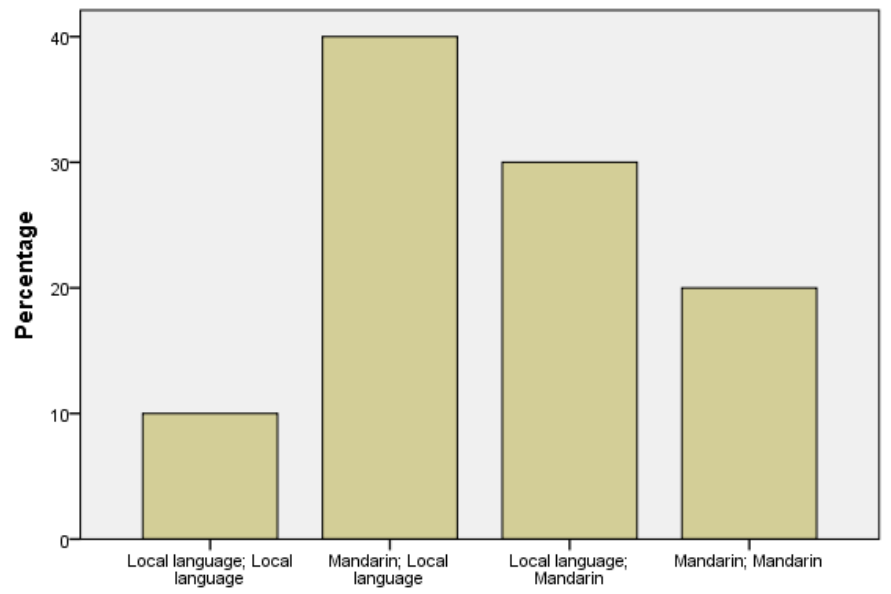

Based on the data of Q2, we can clearly see that the highest percentage of language used inside and outside class at secondary school goes to Mandarin/local language, which is $40 \%$. The lowest percentage of language used inside and outside class at secondary school goes to Local language/Local language, which is $10 \%$ only. Besides, the percentage of the case of Local language/Mandarin used inside and outside class at secondary school is $10 \%$ percent higher than that of Mandarin/Mandarin, which is $20 \%$. The data from the above chart illustrates that Mandarin is mostly spoken inside class at secondary school while most of the time they speak local language outside class. 


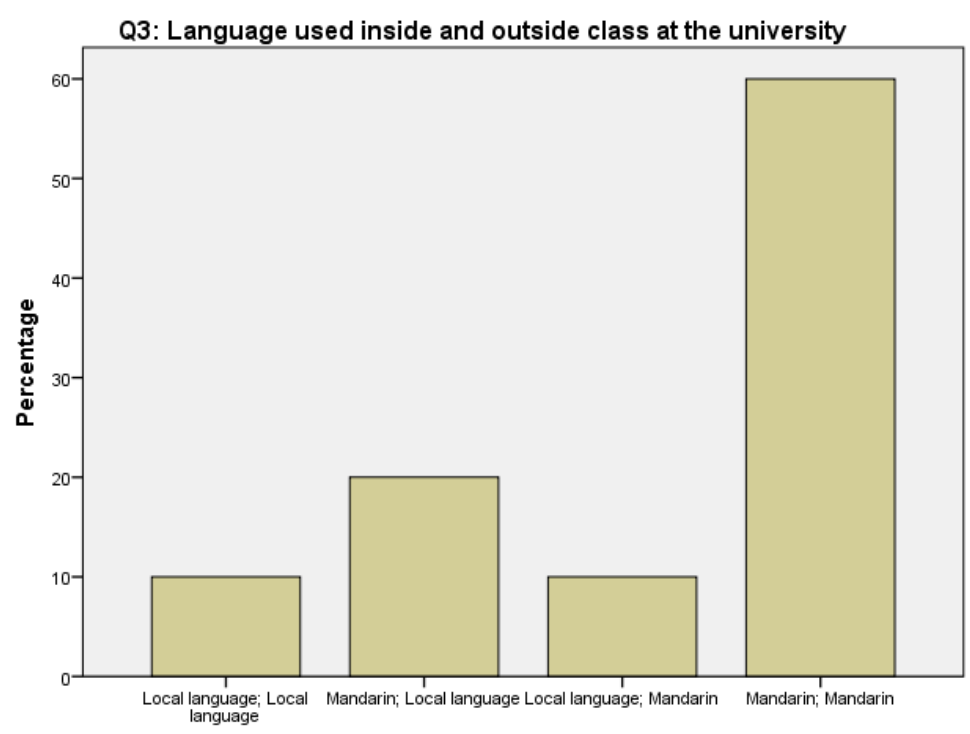

As for the data of Q3, it is shown that the highest percentage of language used inside and outside class at university goes to Mandarin/Mandarin, which is $60 \%$, ranking the highest. The lowest percentage of language used inside and outside class at university goes to Local language/Local language and Local language/Mandarin, which is $10 \%$ only. Besides, the percentage of local language used inside and outside class at university stays between the above cases goes to Mandarin/Local language, which is $20 \%$. The data from the above chart illustrates that Mandarin is mostly spoken inside and outside class at university.

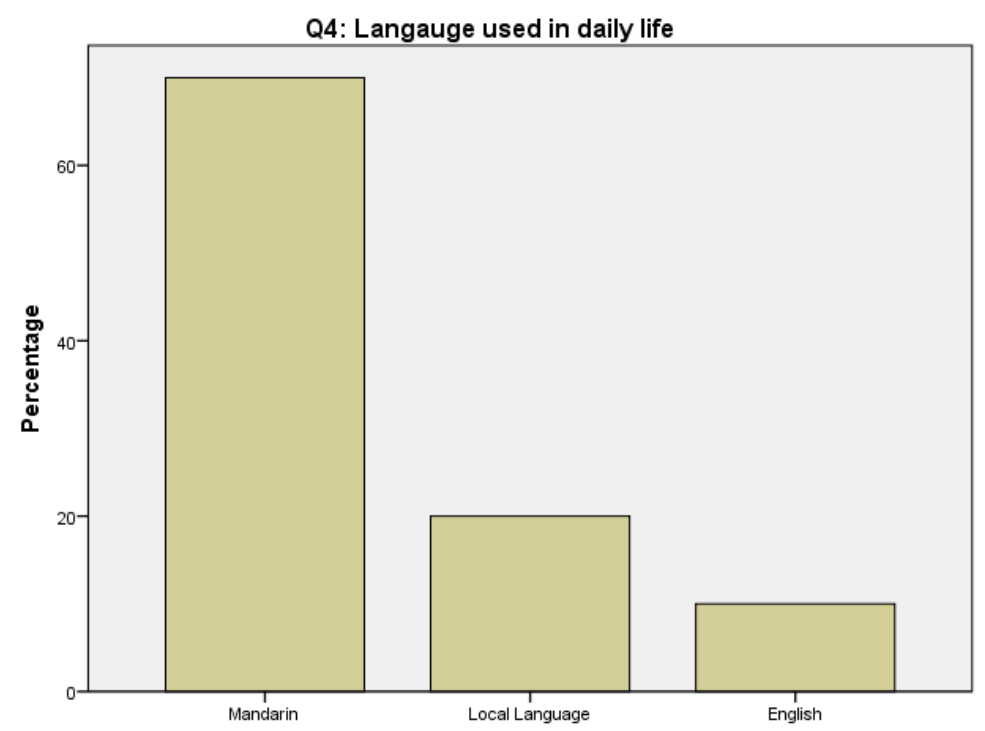

Based on the data of Q4, it is clearly indicated that Mandarin is most frequently used in the participants' daily lives, which is about $70 \%$. Meanwhile, local language is also used in their daily lives, but is only $20 \%$. Besides, English is spoken the least in the participants' daily lives; the percentage is only $10 \%$. The data from Q4 tells us that Mandarin is still the most common language spoken in the daily lives of the participants even though they sometimes use their local language in their daily communication. 


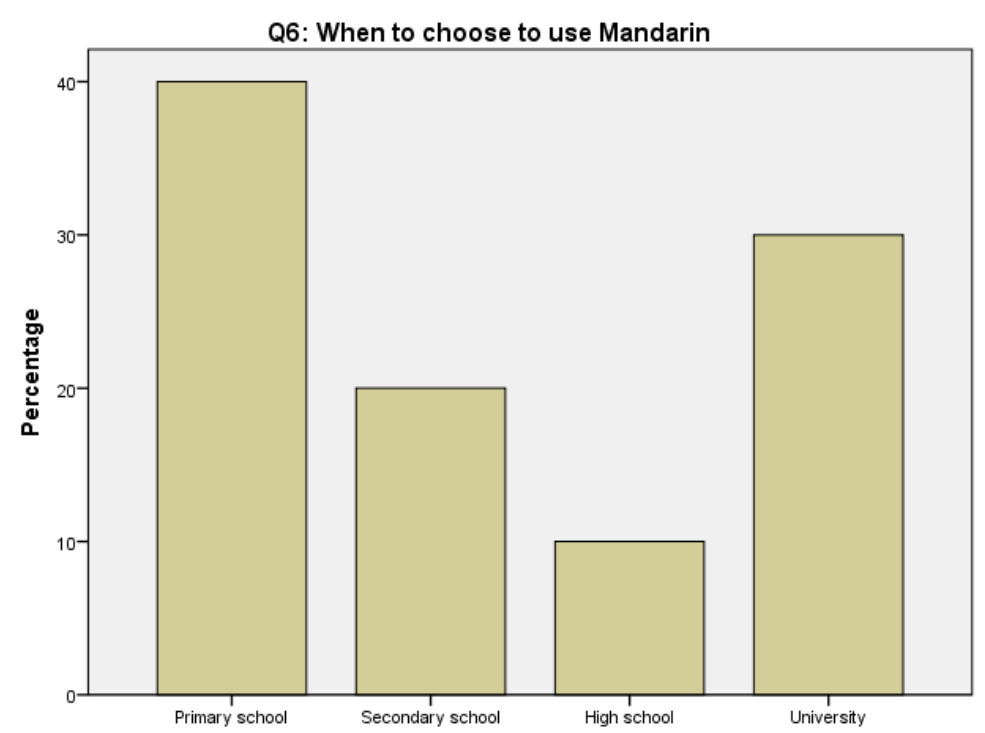

Q6 is telling us the data about the participants' choice of using Mandarin at what time. According to the data of Q6, the percentage of the participants choosing to use Mandarin at primary school is about $40 \%$. And as far as when they are at university, it is less frequently than when they were at primary school, the percentage of which is $30 \%$. The percentages of the participants choosing to use Mandarin at secondary school and at high school are both lower, which are $20 \%$ and $10 \%$ respectively. This is to tell us that when the participants were at primary school they might have already chosen to use Mandarin in their daily language communication and for their language learning.

\section{B. Factors Affecting Language Usage and Endangerment}

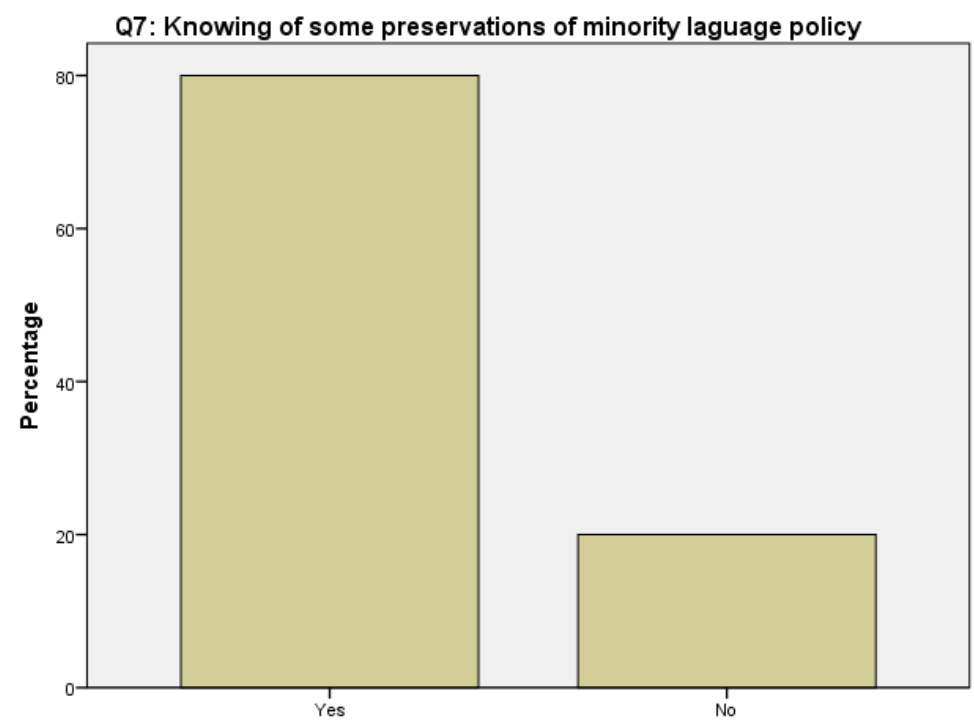




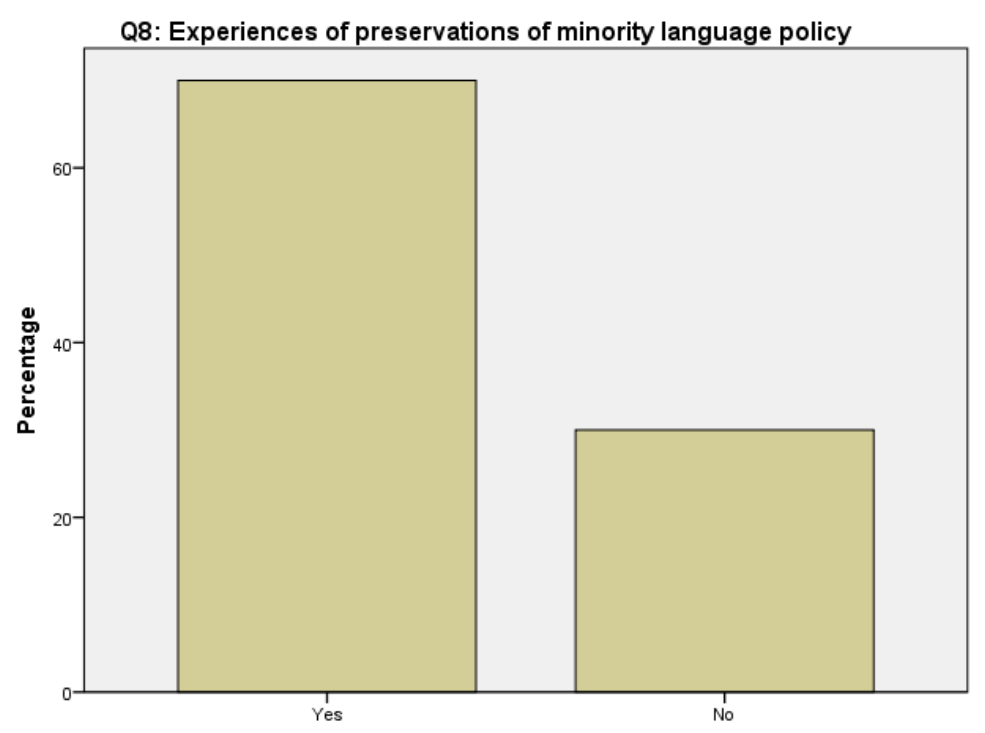

Q9: Main reasons of the minority language endangerment

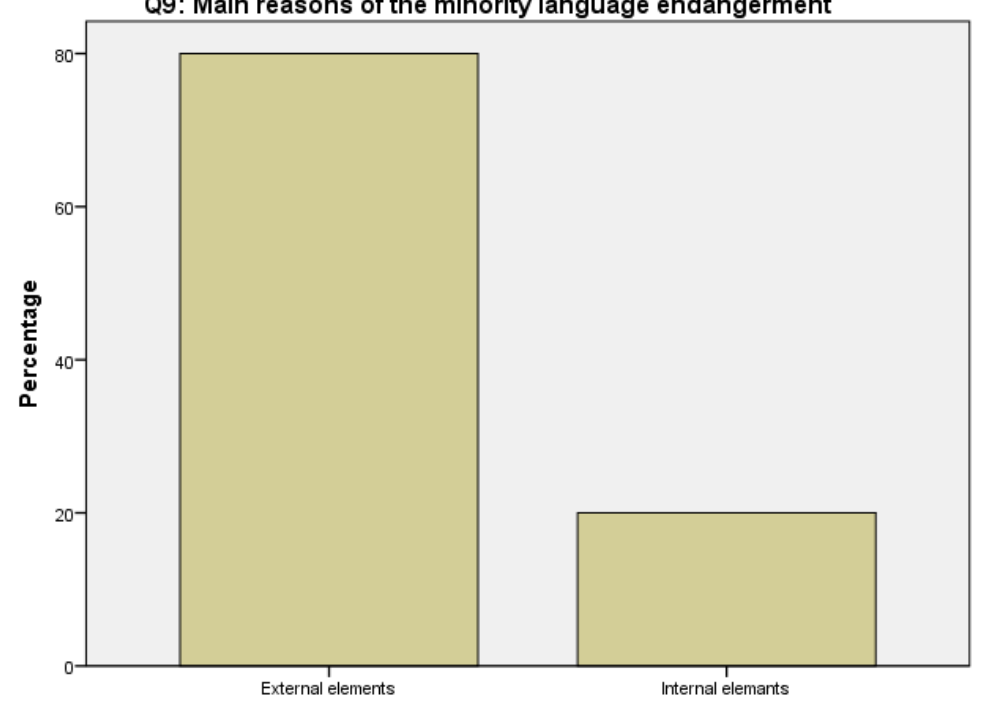

From question 7 to question 9, the main issue is about the knowing of some preservations of minority language policy, the experiences of preservations of minority language policy and the main reasons of minority language endangerment. According to the data of the three questions, it is clearly indicated that when it comes to the knowledge of some preservations of minority language policy, $80 \%$ of the participants know the knowledge. And $70 \%$ of the participants have the experiences of preservations of minority language policy. At the same time, about $80 \%$ of the participants think that external elements are the main reasons of minority language endangerment while those $20 \%$ of the participants think that the main reasons are from internal elements. 


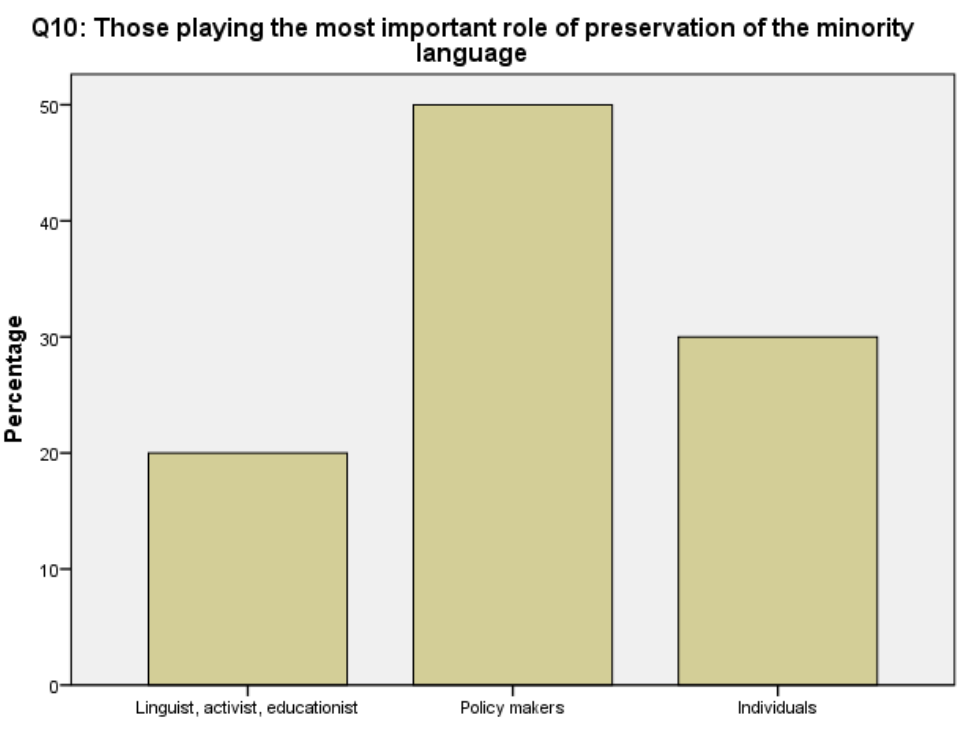

As for those who are playing the most important role of preservation of the minority language, $50 \%$ of the participants think that policy makers play the most important role of the preservation of the minority language. $30 \%$ of the participants think that individuals also play a part. For the role of linguists, activists, educationists, only $20 \%$ of the participants have that idea. Thus it is indicated that policy makers are playing the most important role to preserve the minority language.

C. Relationship among Mandarin, English \& Mother Tongues

Q13: Promotion of Mandarin could affect the endangerment of minority language

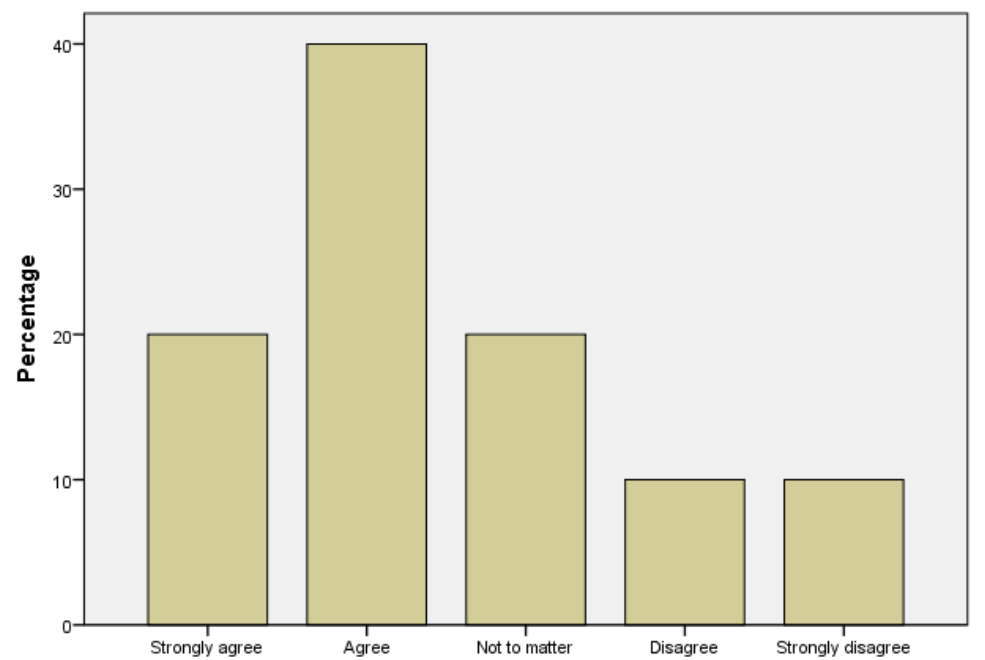

Question 13 is about whether promotion of Mandarin could affect the endangerment of minority language. According to the data, $40 \%$ of the participants think that the promotion of Mandarin could affect the endangerment of the minority language. $20 \%$ of the participants strongly agree with such a fact while $10 \%$ of the participants disagree. The same percentage goes to those who strongly disagree with such a fact. 


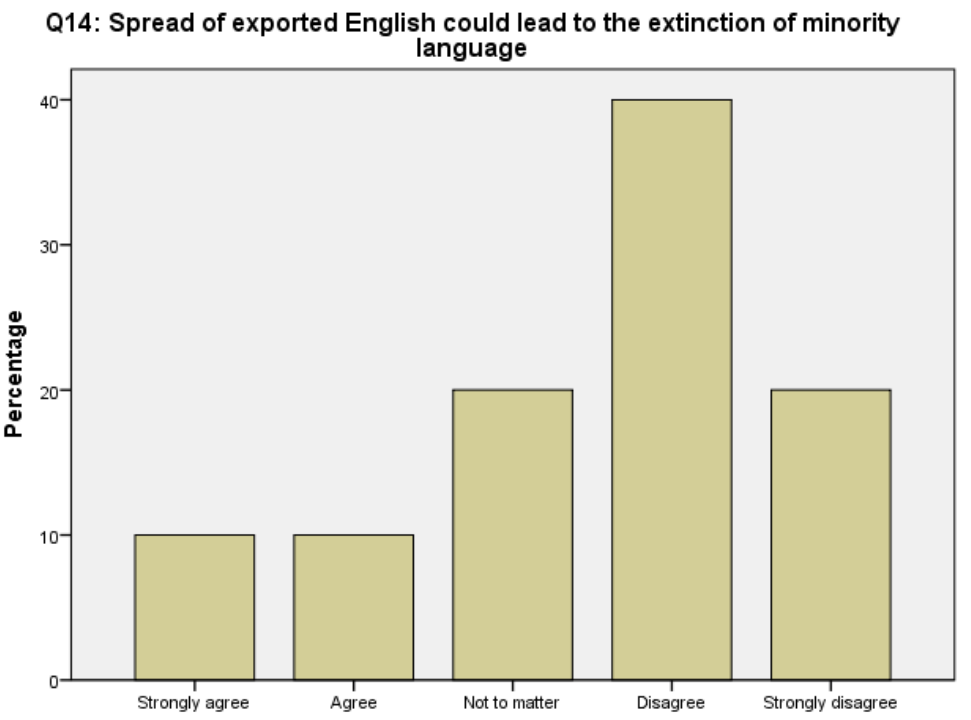

Question 14 is about whether the spread of exported English could lead to the extinction of minority language. It is indicated that $40 \%$ of the participants disagree with such a fact while $20 \%$ of the participants think that they strongly disagreed to admit such a fact. At the same time, only $10 \%$ of the participants strongly agree with such a statement.

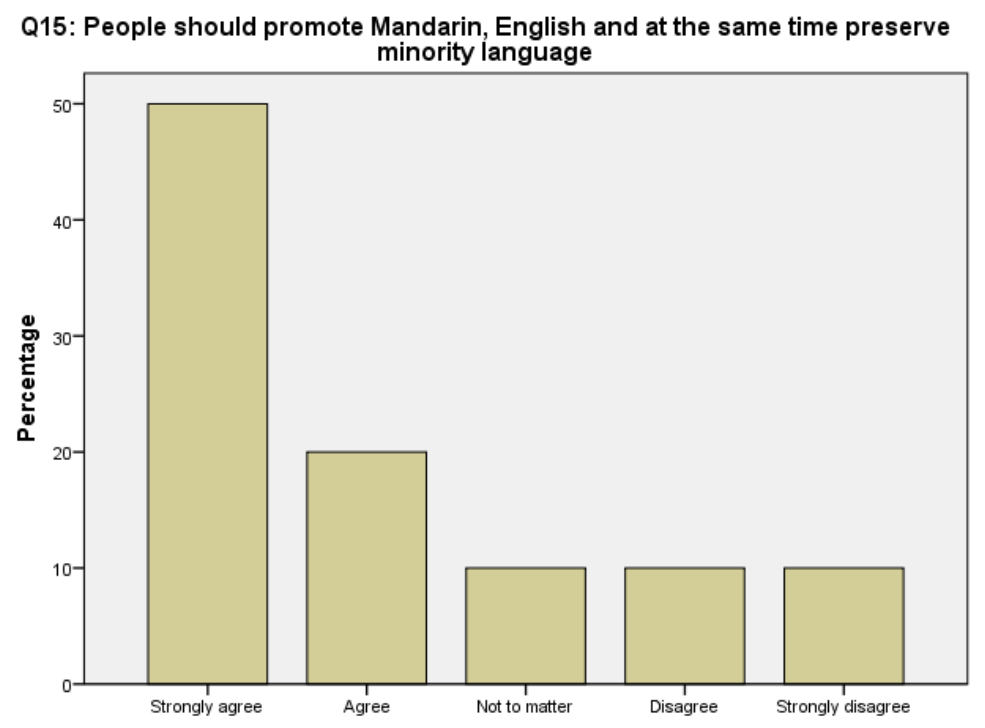

Question 15 mainly shows about whether people should promote Mandarin, English and at the same time preserve minority languages. According to the data of question 15, 50\% of the participants strongly agree to promote Mandarin, English and at the same time preserve minority language. Altogether there are $70 \%$ of the participants agreeing to promote Mandarin, English and at the same time preserve minority language. Based on question 15, we can clearly see that people tend to support the promotion of Mandarin and English while at the same time they also support to preserve their minority language.

\section{CONCLUSION AND RECOMMENDATIONS}

This research concludes what has been discussed above the four parts and gives a conclusive interpretation of the relationship between language acquisition and cultural identity among Chinese minority college students. Meanwhile, an enlightening significance is also introduced, aiming to call for an application of the transition from language acquisition and cultural identity among Chinese minority college students.

\section{A. From Language Acquisition to Cultural Identity}

Accordingly, in China nowadays, Mandarin serving as a common language is generally seen as providing an 
important means by integrating discrete groups of people in China into a common linguistic and cultural system. This process of language acquisition actually involves the so-called legitimation and institutionalization of Mandarin promoted by the government (Zhu, 2003).

Legitimation here refers to the formal recognition accorded to Mandarin by the government. While, institutionalization refers to the process by mass communication, educational practices, which the language comes to be promoted or taken for granted in a wide range of social, cultural and linguistic domains or contexts, both formally and informally (Xiao, 1990).

From language acquisition to cultural identity, the factor of language attitude plays an important role in understanding and expression. The traditional cultural thoughts, national cultural meanings, and cultural identities in the pragmatic system have been affecting the language acquisition all the time. For instance, the basic characteristics of the two languages of Chinese and English embody a different kind of psychological stereotype, value, aesthetics and morality of the respective nations (Chen, 1985). A correct understanding of cultural identity depends on the comprehensive consideration of factors and contexts in language acquisition and language communication.

From language acquisition to cultural identity, language acquisition is an important aspect of language learning. There are two aspects of language learning, one is the understanding of language acquisition, and the other is the understanding of cultural identity. The two complement each other, but they cannot replace each other. The understanding of language acquisition is not an end, but a means to accurately grasp the information conveyed by the identity of the corresponding culture.

In fact, the understanding of language acquisition is not the only means in information conveyed because cultural identity also plays a very important role in it (Hao, 2002). Thus it helps Chinese minority college students learn to know such a fact that, understanding is acting as a communicative activity, which is the process of communicating cultural concepts, cultural thoughts as well as cultural identities between two or more different parties.

\section{B. An Enlightening Significance}

The human society has been progressing since it took place, the development of science and technology and the increasingly close cultural exchanges, the exchanges between different countries, different ethnic groups and different cultural circles are increasing. In modern society, bilingualism and multilingualism are gradually becoming an important part of education (Xiao, 1990).

In China, Mandarin has been of great prestige and importance while other languages or dialects spoken by Chinese have achieved far less attention or been considered in a low prestige (Hao, 2002). After considering all perspectives carefully, it should be concluded that almost all citizens in China may decide to use Mandarin in almost every situation.

Therefore, the transition from language acquisition to cultural identity will also help Chinese minority college students better understand the nature of language structures as well as the language needs of social and cultural activities. Thus it further helps develop effective language instruction and the cultivation of local talents who can carry out language instruction.

Besides, just as Kramsch (2000) maintains, since language is the carrier of culture dissemination and inheritance, a transition from language acquisition to cultural identity is even helpful for Chinese minority college students to understand language acquisition and cultural identity between countries and regions. More importantly, it is also beneficial for further mutual language education and language communication all over the world.

\section{ACKNOWLEDGEMENTS}

The researchers wish to thank the study participants for their contribution to the research, as well as the current and past investigators and staff.

\section{REFERENCES}

[1] Au, T. K. (1983). Chinese and English Counterfactuals: The Sapir-Whorf Hypothesis Revisited. Cognition, 15, $155-187$.

[2] Baggett, H. C. (2016). Student enrolment in world languages: L'Egalité des chances? Foreign Language Annals, 49, $162-179$.

[3] Benson, P. (2017). Ways of seeing: The individual and the social in applied linguistics research methodologies. Language Teaching. First view, published online September 5, 2017. doi.org/10.1017/S0261444817000234

[4] Brecht, R. D. \& Ingold, C. W. (1998). Tapping a National Resource: Heritage Languages in the United States. Washington, DC: National Foreign Language Center Occasional Paper (NFLC).

[5] Burke, L., Crowley, T. \& Girvin, A. (2000). The Routledge language and cultural theory reader. London: Routledge.

[6] Chen, H. (1985). Introduction to Cultural Studies. Shanghai: Shanghai Literature and Art Publishing House.

[7] Cho, G. (2000). The role of heritage language in social interactions and relationships: Reflections from a language minority group. Bilingual Research Journal, 24(4): 333-348.

[8] Couto, H. (2014). "Ecological approaches in linguistics: a historical overview." Linguistic Sciences, 41, 122-128.

[9] Davin, K. J., \& Heineke, A. J. (2017). The Seal of Biliteracy: Variations in policy and outcomes. Foreign Language Annals, 50, 486-499.

[10] Faretta-Stutenberg, M., \& Morgan-Short, K. (2018). The interplay of individual differences and context of learning in behavioral and neurocognitve second language development. Second Language Research, 34, 67-101.

[11] Gay, G. (2000). Culturally responsive teaching: Theory, research and practice. New York: Teachers College Press. 
[12] Hao, D. (2002). Curriculum and Culture: A Postmodern Review. Beijing: Education Science Press.

[13] Haugen, E. (1972). The Ecology of Language. Stanford, CA: Stanford University Press.

[14] Hecht, M. L. (2005). The communication theory of identity: development, theoretical perspective, and future directions. In W. Gudykunst (Ed), Theorizing about Intercultural Communication. Thousand Oaks, CA: Sage.

[15] Jin, S. L. (2002). The Korean Language in America: The Role of Cultural Identity in Heritage Language Learning, Language. Culture and Curriculum, 15(2): 117-133. DOI: 10.1080/07908310208666638

[16] Kramsch, C. (2000). Language and Culture. Shanghai: Shanghai Foreign Language Teaching Press.

[17] Kramsch, C., \& Zhang, L. (2018). The Multilingual Instructor. Oxford, UK: Oxford University Press.

[18] Larsen-Freeman, D. (2018). Looking ahead: Future directions in, and future research into, second language acquisition. Foreign Language Annals, 1-18. doi:10.1111/flan.12314

[19] Lee, S. K. (2001). A qualitative study of the impact of the English language on the construction of the sociocultural identities of ESL speakers. (Unpublished doctoral dissertation). College of Education, University of Houston, Houston, USA.

[20] Lee, S. K. (2003). Multiple Identities in a multicultural world: A Malaysian Perspective. Journal of Language, Identity and Education, 2(3): 137-158.

[21] Lv, M. (2010). A study on the relationship between ethnic identity and language from the perspective of eco-linguistics. (Unpublished Master's Dissertation). Guangxi Normal University, Guilin, China.

[22] Luo, C. (1989). Language and Culture. Beijing: Peking University Press.

[23] Steffensen, S. V. \& Fill, A. (2014). "Ecolinguistics: the state of the art and future horizons." Linguistic Sciences, 41, 6-25.

[24] Steffensen, S. V. \& Fill, A. (2014). “The ecology of language and the ecology of science.” Linguistic Sciences, 41, 1-5.

[25] Stephen, J. C. (2014). Language Sciences, Bio-ecology and Language: A Necessary Unity. Language Sciences, 41, 60-70.

[26] Troyan, F., Cammarata, L., \& Martel, J. (2017). Integration PCK: Modelling the knowledge(s) underlying a world language teacher's implementation of CBI. Foreign Language Annals, 50, 458-476.

[27] Xiao, S. (1990). Education and Culture. Changsha: Hunan Education Press.

[28] Zhu, C. (2003). Bilingualism and the Bilingual Education System and Teaching Mode of Chinese Ethnic Minorities. Journal of Ethnic Education Research, 6, 72-77.

Huanan Su, male, born on 1987-08-03, from Puning City, Guangdong Province, China, is the researcher of this research. Su has earned his master's degree in English Language Teaching (ELT) from Henan University, Kaifeng City, China in 2014. At present, Su is a Ph. D student taking English Language Studies (ELS) in University of the Cordilleras, Baguio City, Philippines. Huanan Su is also a Chinese university lecturer mainly responsible for teaching subject of College English for Chinese university students. Besides, he also teaches subjects such as Vocational College English, College Comprehensive Medical English, Postgraduate Medical Academic English, etc. Su's academic research area is English Language Studies (ELS); specifically he is interested in Teaching of English as a Foreign/Second Language (TEFL/TESL).

Fengyi Ma received her Ed. D degree in Education major in Educational Management from Tarlac State University, Philippines in 2020. She is currently an associate professor in the Office of Foreign Languages, Guilin Medical University, Guilin City, China. Her research interests include education and English. 